\title{
Cost-effectiveness analyses for injury prevention initiatives in low- and middle-income countries
}

Paul A Scuffham

Inj. Prev. 2008;14;217-219

doi:10.1136/ip.2008.019315

Updated information and services can be found at:

http://injuryprevention.bmj.com/cgi/content/full/14/4/217

\section{These include:}

References This article cites 9 articles, 5 of which can be accessed free at: http://injuryprevention.bmj.com/cgi/content/full/14/4/217\#BIBL

\section{Rapid responses You can respond to this article at:}

http://injuryprevention.bmj.com/cgi/eletter-submit/14/4/217

Email alerting Receive free email alerts when new articles cite this article - sign up in the box at service the top right corner of the article

Notes

To order reprints of this article go to:

http://journals.bmj.com/cgi/reprintform

To subscribe to Injury Prevention go to:

http:/journals.bmj.com/subscriptions/ 


\section{Cost-effectiveness analyses for injury prevention initiatives in low- and middle-income countries}

\section{Paul A Scuffham}

Eighty-five percent of the worlds' population live in low- and middle-income countries (LMICs). ${ }^{1}$ An LMIC is defined as a country with a gross national income per capita of $\leqslant$ US\$11 115 in $2006 .^{2}$ Although less than $40 \%$ of the world's vehicles are found in LMICs, more than $85 \%$ of all deaths due to traffic crashes occur in LMICs. ${ }^{3}$ Fatality rates per 100000 population in LMICs are substantially higher than those in highincome countries (HICs). For example, traffic crash fatality rates in the LMICs of Africa and Central/South America are 28.2 and 25.3 per 100000 population, respectively, compared with 16.1 and 16.8 per 100000 population in the HICs of North America and Europe, respectively. ${ }^{4}$ The high numbers of crashes, multiple deaths per crash, and the high mortality from traffic injuries all contribute to the high fatality rates in LMICs. ${ }^{5}$

Deaths due to traffic crashes in LMICs affect children and those of working age (15-44 years) the most (table 1). In the 15-44 year age group, traffic crashes are the leading cause of death in men, accounting for about three-quarters of deaths in this age group. ${ }^{467}$ There are also distinct differences in fatality rates between types of road users and between rural and urban settings within countries. For example, traffic fatalities and injuries mostly occur to pedestrians, passengers and cyclists in LMICs, whereas in the developed world, drivers are most likely to be killed or injured. ${ }^{14}$

Fatality rates due to traffic crashes have increased dramatically in some countries; for example, from 1975 to 1998, rates increased $237 \%$ in Colombia, $243 \%$ in China, and $384 \%$ in Botswana. ${ }^{8}$ These increases are partly due to economic growth and a corresponding growth in the numbers of motor vehicles. ${ }^{1589}$

Correspondence to: Professor P A Scuffham, Chair of Health Economics, School of Medicine, Griffith

University, Meadowbrook, Queensland 4131, Australia; p.scuffham@griffith.edu.au
What is being done about these disparities? In LMICs, the provision of healthcare is relatively limited compared with HICs. For example, most injury patients in LMICs have no access to an orthopedic surgeon, and, as noted by Spiegel et al, this is unlikely to change in the foreseeable future..$^{10}$ Moreover, access to trauma care is usually located in major urban centers, but the majority of traffic crashes in LMICs occur in rural locations. Therefore, given the lack of healthcare services following the occurrence of an injury, interventions to prevent injuries occurring offer the greatest potential benefit, and hence should be given priority. This is not to the exclusion of interventions for treatment after the event, as these must also be developed and considered. We know that much lower traffic crash fatality (and injury) rates can be attained in LMICs, as evidenced by large decreases of these events in HICs over the last few decades; however, a case must be put forward so that initiatives to reduce traffic-related injury will receive much greater priority.

Many interventions, such as motorcycle helmet use and seatbelt use, are intrinsically effective (to some degree) at reducing the traffic-related injury burden. However, there is limited evidence on the effectiveness of population based strategies to increase the uptake of these counter-measures in LMICs. ${ }^{9}$ Moreover, there are relatively few epidemiologists and other experts in LMICs who conduct research into injury prevention. In addition, nationally representative data on the incidence of injuries and outcomesincluding traffic crashes-is often sparse. ${ }^{6}$ Nevertheless, some evidence has been derived from case-control studies and post-hoc ecological analyses." Although these types of evidence are relatively weak compared with evidence from randomized controlled trials, such post-hoc analyses might be the most practical to obtain, and all that is available.
Interventions that are known to be effective and that are potentially transferable (ie, could be adapted) to LMICs are described by Norton et al ${ }^{9}$; these interventions focus on safer roads, safer vehicles and safer people and consider the traditional three E's-education, enforcement, and engineering. However, which intervention should receive priority for implementation and funding usually requires advocacy, presentation of the scientific evidence, and political lobbying.

\section{THE IMPORTANCE OF EVIDENCE ON COST-EFFECTIVENESS}

National resources-people, time, facilities, equipment and knowledge-are limited, and programs compete for these resources. Choices and decisions need to be made regarding how these resources are best utilized. Decision-making should be systematic and based on evidence, rather than on the basis of historical or political patterns which can lead to suboptimal use of resources. ${ }^{11}$ There are several approaches to priority setting, including the burden of disease approach which advocates that the greatest problem receives the greatest priority, and an evidence-based medicine approach where the most effective intervention receives priority. In contrast, economic evaluation is focused on delivering value for money from any intervention. This approach specifies that where resources are limited (ie, everywhere), interventions that produce the greatest value for money should be given the greatest priority.

The fundamental questions asked in the process of economic evaluation are: Is the intervention worth doing compared with other interventions that could be undertaken with the same resources? And which intervention will provide the greatest gains in health outcomes for any additional investment? Cost-effectiveness analysis (CEA) is one approach to address these questions. This, combined with the potential to prevent mortality and morbidity, makes a powerful rationale for determining policy and investments.

Table 1 Traffic crash fatality rates per 100000 population $^{4}$

\begin{tabular}{llr}
\hline Age group & LMICs & HICs \\
\hline 0-4 years & $29.5^{*}$ & 4.5 \\
$5-14$ years & $28.1 \dagger$ & 4.9 \\
$15-44$ years & $32.8 \dagger$ & 20.7
\end{tabular}

${ }^{*}$ South East Asia; †Africa.

HICs, high-income countries; LMICs, low- and middleincome countries. 
A CEA should include evidence on the effectiveness of the intervention, and evidence on the costs of the intervention (including the implementation phase), the cost offsets, and some metric on which the outcomes may be judged and compared across programs competing for the same resources. It is in this context that Bishai and colleagues undertook a CEA of a traffic enforcement program in Uganda. ${ }^{12}$

\section{THE COST-EFFECTIVENESS ANALYSIS FRAMEWORK}

CEA always involves a comparative analysis of alternative courses of action. CEA is one type of full economic evaluation; others are cost benefit analysis (CBA) where outcomes are measured in monetary units, and cost utility analysis (CUA) where outcomes are expressed as qualityadjusted life years (OALYs). ${ }^{13}$ CUA is viewed as a particularly useful technique as it allows for quality of life adjustments to survival based on the values of representative samples of the target population. These are unlike disability-adjusted life years (DALYs) that use age and disability weightings based on the views of a small group of clinicians in Europe. ${ }^{14}$

The CEA, CUA, and CBA differ only in how outcomes are expressed. These approaches all report the additional cost per unit of health gain, calculated as the incremental cost-effectiveness ratio (ICER):

$$
\text { ICER }=\frac{\text { Cost }_{A}-\text { Cost }_{0}}{\text { Effect }_{A}-\text { Effect }_{0}}
$$

where Cost $_{\mathrm{A}}$ is the cost of the new program of interest, Cost $_{0}$ is the cost of the current program (ie, the base case), Effect $_{\mathrm{A}}$ is the outcomes from the new program, and Effect ${ }_{0}$ is the outcomes from the base case. Interventions with the lowest ICER have the greatest return on investment, and therefore should be given priority for implementation. However, it must be stressed that prioritization must always be based on sound establishment of the intervention as safe, effective and acceptable.

Sophisticated techniques are now widely used, such as Markov Chain Monte Carlo simulations, probabilistic sensitivity analysis (PSA), and discrete event simulations. PSA is mandatory in all economic evaluations presented to the National Institute for Health and Clinical Excellence (NICE), ${ }^{15}$ and is a statistical approach with random resampling to quantify uncertainty around both costs and outcomes. ${ }^{13}$ Nevertheless, the ICER is the fundamental metric used to establish value for money relative to other interventions competing for the same resources.

\section{DEVELOPMENT OF COST-EFFECTIVENESS EVIDENCE}

The study by Bishai and colleagues reported in this issue illustrates the difficulties faced in conducting research in LMICs. ${ }^{12}$ These include the weak sources of data for both injury statistics and costs; however, Bishai and colleagues provide an example of how these difficulties can be overcome. Their study provides compelling evidence that traffic enforcement reduces fatalities and results in an increased net income to the Ugandan treasury.

Bishai and colleagues were contracted to evaluate the change in traffic crashes, fatalities, and injuries from a traffic enforcement program, implemented in October 2004, involving four major roads leading into Kampala, Uganda. ${ }^{12}$ The enforcement program included hiring, training, and deployment of 20 traffic officers in four patrol cars equipped with radar. Data from police hand-written records on monthly crash statistics and fatalities were examined and analyzed using ARIMA and Poisson modeling approaches. The difference in fatalities (and fatal crashes) pre- and post-intervention provided necessary evidence on the effectiveness of the intervention (ie, a 17\% reduction in traffic fatalities) for use in an economic evaluation. This type of evidence is no doubt the best possible that can be obtained without undertaking a costly randomized community trial of the enforcement intervention.

Data on the costs of the intervention were obtained from interviews with key informants. Although this is possibly the weakest form of evidence, it was essentially the only evidence that could be obtained. Nevertheless, this information was sufficient for Bishai and colleagues to undertake their CEA.

Bishai and colleagues defined their primary perspective for the study as costs to the police department for the enforcement intervention. It is important to define the perspective used in a CEA study (ie, who incurs the costs) as different perspectives can result in different conclusions being drawn. In their study, there are costs to several other sectors in the economy that have not been taken into account, including the healthcare system for the treatment of injuries, out of pocket costs to patients for travel to access treatment, costs to the police department for the enforcement intervention, costs to the Treasury from traffic citations (which in this study are costsavings, ie income), and indirect costs to the economy from lost production due to premature death. Collectively, along with costs to the police department, these costs would constitute the social cost perspective. ${ }^{13}$ This is the preferred perspective for any analysis of a public health intervention, but is not always possible as noted by Bishai and colleagues. Therefore, their ICER was simplified to fatalities before and after the intervention and zero costs (to the police department) before the intervention.

\section{USE OF ECONOMIC EVALUATION IN LMICs}

Economic evaluation methods are not without limitations; for example, there are contentions around the appropriate discount rate for health outcomes (eg, 3\% versus $10 \%$ ), the measurement and valuation of utility weights for calculating OALYs, and the approach to allocation of capital/overhead costs (eg, straight line method versus accumulated depreciation). However, the greater problems lie in obtaining reasonable data on the costs of healthcare and interventions, and the estimates of morbidity and mortalityespecially in LMICs. Over time these issues will diminish as data collection systems (and economies) develop.

The severe deficiency of good economic evaluations in LMICs is problematic; there is no doubt that more economic evaluations of transferable interventions aimed at reducing traffic crashes and injuries in LMICs will allow resources to be directed to where the greatest health gains can be achieved. Bishai and colleagues have shown that a relatively small investment of $\$ 0.50$ per vehicle per year is sufficient to reduce traffic fatalities by $17 \%$. It is commendable that analyses such as this are increasingly being compiled for LMICs around the globe-and not just for economically advanced countries. More evaluations such as this will allow comparisons to be made between interventions that prevent injury and other health interventions in LMICs, such as HIV prevention and malaria treatment. Such comparisons may clearly show that relatively more resources should be used to tackle transport injury issues. But for this to happen, we need evidence, such as that from Bishai and colleagues. More economic evaluations will provide a better rationale for determining policy and the allocation of resources that ultimately will improve health around the globe. 


\section{Competing interests: None.}

Accepted 1 June 2008

Injury Prevention 2008;14:217-219.

doi:10.1136/ip.2008.019315

\section{REFERENCES}

1. Nantulya VM, Reich MR. The neglected epidemic: road traffic injuries in developing countries. BMJ 2002;324:1139-41.

2. World Bank. Country classification. http://go. worldbank.org/K2CKM78CCO laccessed 25 May 2008).

3. Global Road Safety Network. Moving ahead: emerging lessons. www.grsproadsafety.org (accessed 25 May 2008).
4. Nantulya V, Reich M. Equity dimensions of road traffic injuries in low- and middle-income countries. Inj Control Saf Promot 2003;10:13-21.

5. Hyder AA, Ghaffar A, Masood TI. Motor vehicle crashes in Pakistan: the emerging epidemic. Inj Prev 2000;6:199-202.

6. Hofman K, Primack A, Keusch G, et al. Addressing the growing burden of trauma and injury in low- and middle-income countries. Am J Public Health 2005;95:13-17.

7. Jamison D, Breman J, Measham A, eds. Disease control priorities in developing countries, 2nd edn. New York: Oxford University Press, 2006.

8. Kopitis E, Cropper M. Traffic fatalities and economic growth. Accid Anal Prev 2005;37:169-78.

9. Norton R, Hyder A, Bishai D, et al. Unintentional injuries. In Jamison D, Breman J, Measham A, eds. Disease control priorities in developing countries, 2nd edn. New York: Oxford University Press, 2006.
10. Spiegel D, Gosselin R, Coughlin R, et al. The burden of musculoskeletal injury in low and middle-income countries: challenges and opportunities. J Bone Joint Surg Am 2008;90:915-23.

11. Mitton C, Donaldson C. Health care priority setting: principles, practice and challenges. Cost Eff Resour Alloc 2004;2:3.

12. Bishai D, Asiimwe B, Abbas S, et al. Cost effectiveness of traffic enforcement: case study from Uganda. Inj Prev 2008;14:223-7.

13. Drummond M, Sculpher M, Torrance G, et al. Methods for the economic evaluation of health care programmes, 3rd edn. New York: Oxford University Press, 2005.

14. Arnesen T, Kapiriri L. Can the value choices in DALYS influence global priority-setting? Health Policy 2004;70:137-49.

15. NICE. Guide to the methods of technology appraisal (reference N0515). London: NICE, 2004.

\section{Lacunae}

\section{Women "make better bus drivers"}

One of Sydney's largest bus operators has been granted an exemption from anti-discrimination laws so it can exclusively recruit women as bus drivers. The reason? Women are better drivers and "gentler" on the buses. The exceptional waiver was granted by the NSW Attorney-General after a 9-month campaign by the company. This means that the company can advertise for the next 5 years for women only to train as the next generation of Sydney bus drivers without fear of prosecution.

The managing director Morris Caputi said women were generally more careful with the buses and the passengers. "We find women are gentler on the buses, on the machinery than men, and they relate to passengers better," Mr Caputi said. "We would certainly like to get more women driving." He said that a driver shortage prompted them to offer to cover the \$A2000 training fees and \$A1000 bus license for female recruits in return for 2 years' service. "It's all about getting more women into becoming bus drivers, and to explain to them that it is not that hard to drive a bus," Mr Caputi said. "But to get (female drivers), we need to be able to advertise. We want to show them that buses are not that hard to drive or maneuver. They have power steering."

From The Daily Telegraph (Sydney). Contributed by Ian Scott. 